\title{
Research on the Expectation and Anxiety of the Elderly in the Future
}

\author{
Yen-ni Tsai and Yeajou Shiau
}

\begin{abstract}
The purpose of this study was to explore the population attributes of the elderly, the expectation of senior life, and the impact of anxiety on the mental health of the elderly. This study used a questionnaire survey method, which was conducted by participants who participated in lifelong learning in Taiwan. A total of 348 valid samples were processed and analyzed by statistical methods such as descriptive statistics, t-test, and single-factor variance analysis. The study found that: 1. Retired elderly are generally good about future expectation and future anxiety; 2. In the expectation of the elderly, women, retirees, and low-education are most likely to have an expectation; 3. On the anxiety of elderly female, highly educated, 64-65 years old have a greater need for conversion learning; 4 . The problem of elderly expectation has a mediating effect on the relationship between elderly anxiety problems.
\end{abstract}

Index Terms - Elderly, expectation, anxiety.

\section{INTRODUCTION}

According to Nijhuis (2007), people's learning opportunities are different because of individual differences [1], but the internal incentives are higher than the external motivations, which may be related to the higher inner feelings of the elderly learners. Generally speaking, the psychological growth of the elderly has been completed, and it is understandable to pursue the ideal life in the later stage. Mental health affects the health of life, especially in the post-retirement mental state. Elderly learners expect to obtain more knowledge education and the pursuit of postplanning, and even create a career peak, is enough to cope with the new life and re-employment ability after retirement. This is as the scholar Csikszentmihalyi (2000) put forward the concept of "positive psychology" and pointed out that "positive psychology" plays an important factor in people's mental health [2]. Therefore, it is necessary and important to explore the future expectation and future anxiety of elderly learners.

\section{RESEARCH PURPOSE}

According to the Government's recent 20-year "Human Resources Survey" statistics, it can be seen that for the change of the labor rate in the middle-aged age (45-64 years old), it has been shown that it has been swinging up and down $60 \%$ in 21 years, mainly because of the lower level of the 55-64 age group. The increase in the rate of labor participation in the 45-49 age group showed a mutual increase and decrease. Those who are over 65 years of age

Manuscript received January 8, 2020; revised March 28, 2020.

Yen-ni Tsai and Yeajou Shiau are with Zhaoqing University, China (email: ypwaittim@163.com, shiau.yj@qq.com). have little change due to labor participation, so they are less concerned. Therefore, there is no significant trend (Executive Office, 2016) [3]. The main purposes of this study include:

(1) Analysis of the differences between elderly people with different population attributes for the problem of elderly expectation.

(2) Exploring the differences between elderly people with different population attributes for the problem of elderly anxiety.

(3) Exploring the relationship between the expectation problem of elderly people and the anxiety problem of elderly people.

(4) Based on the results of the study, the appropriate measures for the conversion learning of elderly people are determined.

\section{LITERATURE REVIEW}

\section{A. Related Literature for the Elderly}

According to the Taiwan Employment Service Law, senior citizens are defined as workers over the age of 45 . The Ministry of the Interior is also classified as a middleaged person at the age of 45-65 in the "Statistical Classification of Household Census", while the elderly year is over 65 years old. In addition, the Labor Council has pointed out that middle-aged workers are aged 45 to 54 and 55 to 64 are older workers. Therefore, senior workers refer to workers aged 45 to 64 . Some scholars in Taiwan believe that the age of middle-aged students should be defined between 40 and 45 years old, and the age of seniors should be between 55 and 64 years old (Huang Tongzhen, 2007) [4]. According to the definition of the United Nations World Health Organization, the population over 65 years old is the elderly (WHO, 2002) [5], while the Taiwan Civil Servants Retirement Law and the Ministry of the Interior's Taiwanese population statistics show that they are all 65 years old (Ministry of Education, Education and Social Affairs Division, 2018) [6]. This study is based on the Labor Council's determination that the definition of elderly citizens is mainly for people aged 45 to 64 .

\section{B. Expectation Related Literature}

Yamamoto \& Holloway (2010) pointed out that expectation is internalized through the process of socialization, and individuals will have an impact on interpersonal relationships [7]. Neufeldt (1993) believes that an individual has a desire and confidence for the occurrence of a thing, that is, the meaning of expectation [8]. Eccles (2002) considers successful expectations and value beliefs [9]. These two beliefs influence the important factors of 
individual choice activities, and the expectation is the degree of success that individuals feel they are in this activity. This study is based on Yamamoto \& Holloway's assertion that the expectation is the internal impact of the individual's socialization and internalization process [7].

\section{Anxiety Related Literature}

Sternberg (2001) mentioned in his research that anxiety is a special experience, a process of feeling some doubts, and an emotional response to the fear of an event or injury [10]. Miller (1987) pointed out that anxiety is the perception of self-information, which has the influence of personal inclination and the direction of focus according to the degree of attention [11]. Ke Naiying, He Qigong, and Cai Jijun (1999) [12], when studying the occupational injuries of nursing staff, believe that anxiety is the psychological state of the case when the case is in danger. The psychological state of some things is easy to use words, sometimes the degree of anxiety must first assess the harm degree. This study is based on the definition of Sternberg, which considers anxiety to be a process of feelings of doubt, and a psychological state in which the case is facing problems or uneasiness.

\section{RESEARCH METHOD}

\section{A. Research Architecture}

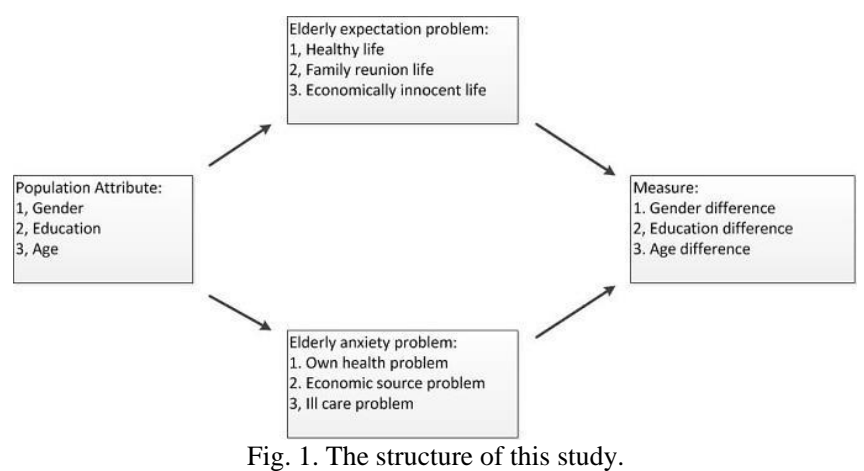

\section{B. Research Hypothesis}

According to the research structure, the research hypotheses established in this study are as follows:

Hypothesis 1: Population attribute has a significant relationship with the expectation of the elderly

Hypothesis 2: Population attributes have a significant relationship with elderly people's concerns

Hypothesis 3: The elderly expectation problem has a mediating effect on the relationship between elderly anxiety.

\section{Research Variable}

The self-variable section is "population attribute": (1) Gender: The gender of the subjects is divided into two categories: "male" and "female". (2) Education: Refers to the academic qualifications in Taiwan. The study is divided into three categories: "Elementary School" and "Middle School". "High school". (3) Age: The current age category of the subject. It is divided into four categories: "45-50 years old", "51-56Four years old and "57-64 years old".

The dependent variables section is divided into two items:
"Elderly expectation Problem" and "Elderly Anxiety Problem". Divided into two parts in the operational definition and measurement tools:

(1) Definition of the problem of elderly expectation: The "Elderly Life Expectation Assessment Form" in Chapter 8 of Professor Wei Huijuan's "Senior Citizens Career Learning" (2015) is used as the main research tool [13]. Based on the survey and evaluation form, this study collects three facets for analysis, namely, "Healthy Life", "Family Reunion" and "Economically Innocent Life". Use questionnaire and interviewing, and semi-structured interview guidelines for data collection.

(2) Definition of the problem of elderly anxiety: Also based on the reference to the "Evaluation Questionnaire for Elderly Anxiety" in the eighth chapter of Professor Wei Huijuan's "Senior Citizens Career Learning" (2015) is used as the main research tool. Based on the survey and evaluation form [13], this study collected three facets for analysis, namely, "Own health problem", "Economic source problem", "Ill care problem". From the subjective ideas and choices of the respondents, predict the actual generation of their ideas.

\section{Research Object}

This study used a Taiwanese senior citizens university (Zhang Deyong, 2001) as the research site [14], and adopted a purposive sample, supplemented by snowball sampling to find research cases. The most suitable ethnic group with the problem of senior expectation and senior anxiety ( $\mathrm{Lu}$ Junhong, 1998) was selected [15], with 125 males and 223 females. The sample selection conditions are as follows:

(1) the number of genders is not limited;

(2) the age between 45 and 64 years old and older;

(3) the case can be communicated and written in Mandarin or Taiwanese;

(4) those who are in the state of retirement age;

(5) willing to accept the assessment scale and shallow interviewers;

(6) have active learning motivation;

(7) the degree of education is limited to the elementary school level.

\section{Research Result}

A. Analysis of the Differences between the Elderly with Different Population Attributes and the Expectations of the Elderly

\section{1) Gender}

The study finds that the expectations of elderly people are still different. In the gender part, the number of men is 125 , the mean is .35 , and the number of women is 223 , with a mean of .64. The number of men who have "no expectations" is 7 and the mean is .056. The number of women is 11 . The mean is .049 . It can be found that the ratio of men is more than that of women. The number of men who have "a little expectation" is 17 people, and the mean is .136. The number of women is 38 , and the mean is .170 . It can be found that the ratio of women is more than that of men. In the "sometimes expected" section, the number of men is 58, the mean is .646, and the women is 65 , the mean is .291. It can be found that men's ratio is three times more than 
women. In the "often expected" section, the number of men is 31 , the mean is .248 , the number of women is 85 , the mean is .381 , and it can be found that there are more women than men. From the "very expected" section, the number of men is 12 , the mean is 0.096 , the number of women is 26 , with a mean of 0.1166 , and it can be found that there are more women than men. According to hypothesis 1: the population attribute has a significant relationship with the elderly expectation problem, the gender difference has a significant difference to the elderly expectation problem. In the gender part, in the single factor analysis, because $\mathrm{P}<$ 0.05 , the level of significance is reached, and it can be found that the "a little expectation" ANOVA P $=.042$, "sometimes expected" variation in the homogeneity test, $\mathrm{P}=.002$, ANOVA P $=.000$, "often expected" ANOVA $\mathrm{P}=.026$, all reach a significant level. From the descriptive statistics, it can be seen that the number of people who have "a little expectation", "sometimes expect" and "often expect" is a significant result. From this, it can be inferred that the number of people who "sometimes expect" is mostly male. The number of people who have "a little expectation" and "often expect" is mostly women. It can be found that women's expectations are more extreme, and will be some expectations or extreme expectations.

\section{2) Education}

This study finds that there are still differences in the degree of expectations of elderly people. In the education part, the number of people in elementary school is 69 , in the middle school is 105 , and in high school is 174 . In the "no expectations" section, the number of people in elementary school is 9 and the mean is .130. the middle school is 9 , and the mean is .085 , the high school is 11 people, the mean is .063. and the ratio of elementary school is the highest. In the "a little expectation" section, the number of people in elementary school is 26 , the mean is .377 , the middle school is 21 , the mean is .2 , the high school is 38 , the mean is .218 , and the ratio of the people in elementary school is the highest. In the "sometimes expected" section, the number of people in elementary school is 22 , the mean is .319 , the middle school is 42 , the mean is .4 , the high school is 44 , the mean is .252, and the ratio of people in the middle school is the highest. In the "often expected" section, the number of people in elementary school is 9 and the mean is .013, the middle school is 27 , the mean is .257 , the high school is 68 , the mean is .391, and the ratio of people in high school is the highest. According to hypothesis 1: the population attribute has a significant relationship with the elderly expectation problem, and the difference in education has a significant difference to the elderly expectation problem. In the education part, in the single factor analysis, because $\mathrm{P}<0.05$, the level of significance is reached, and it can be found that the "a little expectation" ANOVA $\mathrm{P}=.021$, the variation number homogeneity test $\mathrm{P}=.027$, "sometimes expected" ANOVA $\mathrm{P}=.000$, the variance number homogeneity test $\mathrm{P}$ $=.001$, have reached a significant level. From descriptive statistics, it is known that there are more people who have "a little expectation" and "sometimes expected", and obviously achieve significant results. It can be inferred that the number of elderly expectations is higher in elementary school and middle school than in high schools.

\section{3) Age}

The study finds that the degree of expectation at the age of elderly is still different. In the age part, the number of people aged 45-50 is 9 people, the number of 51-56 is 98 , and the number 57-64 is 241. In the "no expectations" section, the number of people aged $45-50$ is 0 , the number of $51-56$ is 2 , the mean is .020 , the number of $57-64$ is 21 , the mean is .087 , and the ratio of people in aged 57-64 is the highest. In the "a little expectation" section, the number of people aged $45-50$ is 1 , the mean is .111 , the number of 51 56 is 14 , the mean is .143 , the number of people aged $57-64$ is 46 , the mean is 0.191 , and the ratio of people aged 57-64 is the highest. In the "sometimes expected" section, the number of people aged 45-50 is 5 , the mean is .555 , the number of $51-56$ is 43 , the mean is .439 , the number of 57 64 is 53 , the mean is .220 , and the ratio of people in aged 45-50 is the highest. In the "often expected" section, the number of people aged $45-50$ is 2 , the mean is 0.222 , the number of $51-56$ is 31 , the mean is .316 , and the number of $57-64$ is 73 , the mean is .303, the ratio of people in aged 5156 is the highest. In the "very expected" section, the number of people aged $45-50$ is 1 , the mean is .111 , the number of $51-56$ is 8 , the mean is .082 , the number of $57-64$ is 48 , the mean is .199, and the ratio of people in aged 57-64 is the highest. According to Hypothesis 1: Population attribute has a significant relationship with the expectation of the elderly, the difference between the age and the age expectation problem is significant. In the single factor analysis, because $\mathrm{P}<.05$, the level is significant, it can find that "sometimes expected" $=.024$, "often expect" $\mathrm{P}=.035$, all at a significant level. From descriptive statistics, it is known that "sometimes expected" and "often expect" are mostly 45-50 years old and 51-56 years old. It is inferred that the age expectation of 45-56 years old is more obvious than other age groups.

\section{B. Exploring the Difference of Elderly People with Different Population Attributes}

\section{1) Gender}

This study finds that there are still differences in the degree of anxiety in elderly age. In the gender part, the number of men is 125 , the mean is .35 , and the women is 223 , the mean is .64 . The number of the men with "not anxious" is 11 , the mean is .088 , and the number of the women is 8 , the mean is .036 , and it can be found that the ratio of men is more than women. The number of men with "a little anxiety" is 15 , the mean is .12 , and the number of women is 44 , the mean is .197 . It can be found that the ratio of women is more than men. In the "often anxious" section, the number of men is 43 , the mean is .344 , and the number of women is 71 , the mean is 0.318 . The ratio of men is more than women. From the "very anxious" section, the number of men is 9 , the mean is .072 , and the number of women is 23 , the mean is .103 . The ratio of women is more than that of men. According to Hypothesis 2: Population attribute has a significant relationship with the problem of elderly anxiety, the difference in gender has a significant difference to the problem of elderly anxiety. In the gender part, in the single factor analysis, $\mathrm{P}<0.05$ is a significant level. It can be found that the "little anxiety" ANOVA P = .033, the "sometimes anxious" variation in the homogeneity test, $\mathrm{P}=.000$, 
ANOVA P $=.001$, and "often anxious" ANOVA P $=.018$ have reached a significant level. From the descriptive statistics, it can be seen that the number of people who have "a little anxious", "sometimes anxious" and "often anxious" is the majority, and obviously achieves significant results. It can be inferred that the number of people with "a little anxiety" is mostly women and the number of people who "somewhat anxious" and "often anxious" is mostly men. It can be found that men's anxiety is significantly higher than that of women, and women's anxiety is relatively low.

\section{2) Education}

This study finds that there are still differences in the degree of anxiety in elderly age. In the education part, the number of people in elementary school is 69 , in the middle school is 105, and in high school is 174. In the "no anxious" section, the number of people in elementary school is 5 , the mean is .072 , the middle school is 12 , the mean is .114 , the high school is 18 , the mean is .103 , and the ratio of the number of people in the middle school is the highest. In the "a little anxious" section, the number of people in elementary school is 13 and the mean is .188, the middle school is 13 , the mean is .123 , the high school is 40 , the mean is .230 , and the ratio of the number of people in high school is the highest. In the "sometimes anxious" section, the number of people in elementary school is 32 , the mean is .230 , the middle school is 29 , the mean is .276 , the high school is 56 , the mean is .322 , and the ratio of the number of people in high school is the highest. In the "often anxious" section, the number of people in elementary school is 12 , the mean is .174 , the middle school is 33 , the mean is .314 , the high school is 49 , the mean is .282 , the ratio of the number of people in middle school is the highest. In the "very anxious" section, the number of people in elementary school is 7 , the mean is .102 , the middle school is 18 , the mean is .171 , the high school is 11 , the mean is .006 , and the ratio of the people in middle school is the highest. According to Hypothesis 2: There is a significant relationship between the population attribute and the anxiety problem of elderly age, and the difference in education is significantly different from the problem of elderly anxiety. In the part of the education, in the single factor analysis, because $\mathrm{P}<.05$, the level of significance is significant, and it can be found that "sometimes anxious" ANOVA P $=.011$, the variance number homogeneity test $\mathrm{P}=.020$. ANOVA $\mathrm{P}=.000$ for the "often anxious" and the homogeneity test $\mathrm{P}=.000$ for the variability has reached a significant level. From the descriptive statistics, the number of people who are "sometimes anxious" and "often anxious" is the majority, and the results are obviously significant. It can be inferred that the degree of anxiety in high school and middle school is more obvious than the number of people in elementary school.

\section{Exploring the Relationship Analysis between the Elderly Expectation Problem and the Elderly Anxious Problem}

This study is based on the "Elderly Life Expectations Assessment Form" in Chapter 8 of Professor Hui Juan's "Senior Age Life Study" (2015) [13], which is the main research tool analysis, and the 286 respondents with the highest elderly expectation. Using the "Evaluation
Questionnaire for Elderly Anxiety" survey and SPSS statistical analysis, the single factor analysis of the population attributes of these respondents and the anxiety problem of elderly, $\mathrm{P}<.05$, reached a significant level (* indicates $\mathrm{P}<0.05$, ** indicates $\mathrm{P}<0.01$, *** indicates $\mathrm{P}<0.001)$.

Use single factor analysis of gender and elderly anxiety problems, in the "own health problem" section, there is a significant (.011) in the analysis method of the homogeneity test of the variance number. In the ANOVA analysis method, .524 appears, and its $\mathrm{F}$ value is .060; in the "economic sources problem" section, there is significant (.128) in the analysis method of the homogeneity test of the variance number. In the ANOVA analysis method, .663 appears, and its F value is .148; in the analysis method of the homogeneity test of the variance number, in the part of the "ill care problem", significant (.034) appeared, and in the ANOVA analysis method, .271 appeared, and its $F$ value was 1.122 (see Table I).

TABLE I: Single FACTOR ANALYSIS TABLE FOR GENDER AND OLD AGE CONCERNS

\begin{tabular}{|c|c|c|c|}
\hline \multirow{4}{*}{$\begin{array}{l}\text { 1." Our Health } \\
\text { Issues" } \\
\text { section }\end{array}$} & \multicolumn{3}{|c|}{ Analytical method } \\
\hline & & Significance & F value \\
\hline & $\begin{array}{c}\text { Variability } \\
\text { homogeneity } \\
\text { test }\end{array}$ & $.011 *$ & \\
\hline & ANOVA & .524 & .060 \\
\hline \multirow{3}{*}{$\begin{array}{l}\text { 2.'Economic } \\
\text { Issues " } \\
\text { section }\end{array}$} & 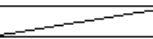 & Significance & Fvalue \\
\hline & $\begin{array}{c}\text { Variability } \\
\text { homogeneity } \\
\text { test }\end{array}$ & .128 & \\
\hline & ANOVA & .663 & .148 \\
\hline \multirow{3}{*}{$\begin{array}{l}\text { 3. "Illness care } \\
\text { problem" } \\
\text { section }\end{array}$} & $\ldots$ & Significance & F value \\
\hline & $\begin{array}{c}\text { Variability } \\
\text { homogeneity } \\
\text { test }\end{array}$ & $.034 *$ & \\
\hline & ANOVA & .271 & 1.122 \\
\hline
\end{tabular}

TABLE II: SINGLE FACTOR ANALYSIS OF EDUCATION AND OLD AGE CONCERNS

\begin{tabular}{|c|c|c|c|}
\hline \multirow{4}{*}{$\begin{array}{l}\text { 1. "Our Health } \\
\text { Issues" section }\end{array}$} & \multicolumn{3}{|c|}{ Analytical method } \\
\hline & 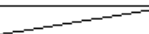 & Significance & F value \\
\hline & $\begin{array}{c}\text { Variability } \\
\text { homogeneity } \\
\text { test }\end{array}$ & $.014^{*}$ & \\
\hline & ANOVA & .413 & .612 \\
\hline \multirow{3}{*}{$\begin{array}{l}\text { 2."Economic } \\
\text { Issues" section }\end{array}$} & & Significance & F value \\
\hline & $\begin{array}{c}\text { Variability } \\
\text { homogeneity } \\
\text { test }\end{array}$ & $.018 *$ & \\
\hline & ANOVA & .120 & 1.217 \\
\hline \multirow{3}{*}{$\begin{array}{l}\text { 3. "IIIness care } \\
\text { problem" } \\
\text { section }\end{array}$} & 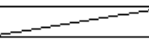 & Significance & F value \\
\hline & $\begin{array}{c}\text { Variability } \\
\text { homogeneity } \\
\text { test }\end{array}$ & .222 & \\
\hline & ANOVA & .257 & 1.314 \\
\hline
\end{tabular}

Use single factor analysis of education and senior anxiety problems, in the "own health problem" section, it is significant (.014) in the analysis method of the homogeneity test of the variance, which appears in the ANOVA analysis method. .413 appears, and its $\mathrm{F}$ value is .612; in the "economic sources problem" section, there is significant (.018) in the analysis method of the homogeneity test of the variance number. In the ANOVA analysis method, .120 appears, and its $\mathrm{F}$ value is 1.217 , in the analysis method of the homogeneity test of the variance number, there is significant (.222) in the part of the "ill care problem", and in the ANOVA analysis method, .257 appears, and its $\mathrm{F}$ value 
is 1.314 (see Table II).

Use single factor analysis of age and elderly anxiety problems, in the "own health problem" section, it is significant in the analysis method of the homogeneity test of variance (.048), and in the ANOVA analysis method. .629 appears, its $\mathrm{F}$ value is .597; in the "economic sources problem" section, it is significant (.021) in the analysis method of the homogeneity test of the variance number, and in the ANOVA analysis method, .266 appears, and its $\mathrm{F}$ value is 1.325 ; in the analysis method of the homogeneity test of the variance number, there is significant (.879) in the part of the disease care problem, and in the ANOVA analysis method, .452 appears, and its F value is .296 (see Table III).

TABLE III: SINGLE FACTOR ANALYSIS TABLE FOR AGE AND OLD AGE CONCERNS

\begin{tabular}{|c|c|c|c|}
\hline \multirow{4}{*}{$\begin{array}{l}\text { 1."Our Health } \\
\text { Issues" section }\end{array}$} & \multicolumn{3}{|c|}{ Analytical method } \\
\hline & & Significance & Fvalue \\
\hline & $\begin{array}{c}\text { Variability } \\
\text { homogeneity } \\
\text { test }\end{array}$ & $.048^{*}$ & \\
\hline & ANOVA & .629 & .597 \\
\hline \multirow{3}{*}{$\begin{array}{l}\text { 2."Economic } \\
\text { Issues " section }\end{array}$} & & Significance & Fvalue \\
\hline & $\begin{array}{c}\text { Variability } \\
\text { homogeneity } \\
\text { test }\end{array}$ & $.021 *$ & \\
\hline & ANOVA & .266 & 1.325 \\
\hline \multirow{3}{*}{$\begin{array}{l}\text { 3."Illness care } \\
\text { problem" } \\
\text { section }\end{array}$} & & Significance & Fvalue \\
\hline & $\begin{array}{c}\text { Variability } \\
\text { homogeneity } \\
\text { test }\end{array}$ & .879 & \\
\hline & ANOVA & .452 & 296 \\
\hline
\end{tabular}

According to the statistical data, $\mathrm{P}<.05$, reaching a significant level, can be found in the population attribute, in terms of gender, and the "own health problem" section of the elderly anxiety problem, found that $\mathrm{P}=.014$, reached a significant level, and the "ill care problem" section found that $\mathrm{P}=.034$, which also reach a significant level. In terms of education, the "own health problem" section of the problem of elderly anxiety finds that $\mathrm{P}=.014$, which reaches a significant level and "economic source problem", finds that $\mathrm{P}=.018$, also reaches a significant level. In terms of age, the "own health problem" section of the problem of elderly anxiety finds that $\mathrm{P}=.048$, which is a significant level, and the "economic source problem" section finds $\mathrm{P}$ $=.021$, which also reaches a significant level.

From the above information, it can be seen that in the relationship between "elderly expectation problem" and "elderly anxiety problem", the variables that have an intermediary effect are "gender", "education" and "age". "Education" and "age" affect the problem of elderly anxiety. In the "own health issues" and "economic resource problem" sections, only the "gender" variables affect the "own health problem" and "ill care problem" sections of the elderly anxiety problem.

\section{Based on the Research Results, the Corresponding Measures for the Appropriate Conversion Learning of the Elderly}

In this study, the "Elderly Life Expectation Assessment Form" and the "Evaluation Questionnaire for Senior Anxiety" are used to collect information, and semistructured interviews are used to guide the collection of case data. It can be found that the method of catalytic conversion learning organized by Baumgartner (2003) [16] and the conversion learning of Mezirow, Jack (1975) [17] can improve the negative thinking of elderly retirees. To promote the part of conversion learning, the researchers analyzed and formulated appropriate response measures for the results of the study, as follows.

Hypothesis 1 results show that population attributes have a significant relationship with the elderly expectation problem. Therefore, in the gender response measures, the number of people who "sometimes expected" is mostly men and the number of people who have "a little expectation" and "often expected" is mostly women. From this, it can be found that women's expectations are more extreme, with only a little expectation or extreme expectation. The number of people with "required expectations" and "sometimes expectation" is a majority and obviously achieves significant results. It can be inferred that the number of elderly in the elemental school and middle school is higher than that in high school. The age-appropriate measures, based on "sometimes expected" and "often expected", are mostly 45 50 years old and 51-56 years old. It is inferred that the elderly expectation of 45-56 years old is more obvious than other age groups.

Hypothesis 2 results show that population attributes have a significant relationship with the problem of elderly anxiety. Therefore, 1 . The gender response measures, the number of people with "a little anxiety" are mostly women. The number of "sometimes anxious" and "often anxious" is mostly men. It can be found that the anxiety value of men is significantly higher than that of women, and the degree of anxiety of women is relatively low. Therefore, special attention should be paid to women psychological counseling and counseling. In the response measures of 2 . education, the number of "sometimes anxious" and "often anxious" is the majority, and the results are clearly significant. It can be inferred that the number of elderly in high school and middle school is more than the number in elementary school. In the age-related measures, "sometimes anxious" and "often anxious" are mostly 45-50 years old and 57-64 years old. It is inferred that the age of 45-56 years old is significantly lower than other age groups.

Hypothesis 3 results show that the elderly expectation problem has a mediating effect on the relationship with the elderly anxiety problem. Therefore, 1. Gender response measures are based on the "own health problem" in gender and elderly anxiety issues, $\mathrm{P}=.014$ appears, reaching a significant level, and in the section on "ill care problem", $\mathrm{P}=.034$ appears, which also reaches a significant level. In the measures of education, in the "own health problem" section of education and elderly anxiety problems, $\mathrm{P}=.014$ appears, which reaches a significant level and the "economic source problem" section, $\mathrm{P}=.018$ appears, also reaches a significant level. In age response measures, $\mathrm{P}=.048$ appears in the "own health problem" section of the elderly anxiety problem, which reached a significant level. The "economic source problem" section, $\mathrm{P}=.021$ appears, also reaches a significant level.

Finally, in formulating the appropriate "conversion learning" response measures, according to hypothesis 1 of the research results, the population attribute has a significant relationship with the elderly expectation problem. Therefore, 
the response measures in the aspect of gender differences, adult education units and retirees counseling unit should give strengthen care and counseling for elderly female retirees. In terms of the response measures of the education, the faculty or administrative units should strengthen the training course for the "expected career" of the elderly of elementary school and middle school. In terms of agerelated measures, counseling agencies should take the initiative to assist 45-56-year-old retirees with health, learning, economics, companionship, career and other expectations.

According to hypothesis 2 of the research results, the population attribute has a significant relationship with the elderly anxiety problem. Therefore, in response to the gender difference, the community-related teaching institutions should strengthen the learning channels and psychological counseling opportunities for male elderly retirees. In terms of education response measures, senior-age teaching institutions should strengthen the tutoring programs and conversion learning pathways for adult education institutions, retired elderly who have high school or middle school education. In terms of age-related measures, community or age-related teaching institutions should take the initiative to assist with applications for schooling opportunities and social welfare measures for middle-aged and elderly people aged 45-56 and 57-64. According to hypothesis 3 of the research results, the age-related expectation problem has a mediating effect on the relationship between elderly anxiety problems. In response to the gender differences, the research-conversion learning units and medical-related systems strengthen the gender differences in elderly age, especially in the "own health problem" and research on the "ill care problem" section. In terms of educational measures, enterprises or public agencies should be aware of the differences in elderly education and anxiety among the elderly, and have a critical influence on the "own health problem" and "economic source problem". In terms of age-related measures, institutions operating senior education should be aware of the differences in age groups and have a strong correlation with the "own health problem" and "economic source problem" in the issue of elderly anxiety need to coach their more successful ways of conversion learning.

\section{CONCLUSION AND SUGGESTION}

\section{A. Conclusion}

This study is for elderly retirees. In hypothesis 1 . Population attributes have a significant relationship with the elderly expectation problem, and the significant attribute results are 1. Gender: Female, 2. Education: Elementary school, Middle school, 3. Age: 45-50 years old and 51-56 years old, it can be found that women, retirees, and loweducation people are most likely to be psychologically stressed by the problems they expect. In hypothesis 2 . Population attribute has a significant relationship with the problem of elderly anxiety. The significant attribute results are 1. Gender: Female, 2. Education: High school, Middle school, 3. Age: 45-50 years old and 57-64 years old, it can be found that women, high-education, 64-65 years old people are a need for conversion learning.

\section{B. Suggestion}

Advice for elderly retirees: Everyone has work experience and a philosophy of life. As long as there is an optimistic and positive attitude, and with appropriate conversion learning, it will definitely reduce the chances of worrying about stress and increasing good expectations, and more likely to create the second stage of life.

Advice to the government and related companies: If the for-profit institutions and non-profit organizations can work together with the government's public service system, they can fully assist the elderly retirees to once again face the courage of the future.

Suggestions for further research: In terms of research content, qualitative research methods can be used to compare the core ideas of respondents. In the field of research, it is recommended that follow-up researchers can choose advanced mind-related research to improve the psychological level of adult counseling, and also influence the government's attention.

\section{CONFLICT OF INTEREST}

The authors declare no conflict of interest.

\section{AUTHOR CONTRIBUTIONS}

Yen-Ni Tsai conducted the research, analyzed the data and wrote the paper in draft; Yeajou Shiau translated the paper and had approved the final version.

\section{REFERENCES}

[1] J. F. H. Nijhuis, "A structural equation model analyzing the relationship of student achievement motivations and personality factors in a range of academic subject- matter areas," Contemporary Educational Psychology, vol. 32, no. 1, pp. 105-131, 2007.

[2] M. Csikszentmihalyi, "Positive psychology: An introduction," American Psychologist, vol. 55, no. 1, pp. 5-14, 2000.

[3] Taiwan Executive Office. (2016). [Online]. Available: https://www.dgbas.gov.tw/

[4] T. Huang, "Discussion on the change of employment environment and countermeasures under the trend of aging," Taiwan Labor Bimonthly, vol. 5, pp. 18-29, 2007

[5] World Health Organization (WHO), "Current and future long-term care needs," Geneva: WHO, 2002.

[6] Ministry of Education, Education and Social Affairs Division, Taiwan. (2018). Middle-age development plan for senior education. [Online]. Available:

https://ws.moe.edu.tw/Download.ashx?u=C099358C81D4876C72569 5F2070B467E436AA799542CD43DB90BFC8C0D410D52889B6E7 2788D43AA70C66B5425B71A92392083664BAAB3463F6B158D0C 61C6935FA4881F9116094D28D0B5E9FFF291DF\&n=FAEE177738 E8A847F600DA1EE0B842E497287C3144F4029ABDD4E6E3A376 415B\&icon=.pdf

[7] Y. Yamamoto and S. D. Holloway, "Parental expectations and children's academic performance in sociocultural context," Education Psychological Review, vol. 22, pp. 189-214, 2010.

[8] V. Neufeldt, Webster 's New Word Dictionary 01American English NY: Simon \& Schuster Inc., 1993.

[9] J. S. Eccles and A. Wigeld, "Motivation beliefs, values and goals," Annual Review of Psychology, vol. 53, pp. 109-132, 2002.

[10] R. J. Sternberg, Psychology: In Search of the Human Mind, Orlando: Harcourt, 2001, pp. 362-411

[11] S. Miller, "Monitoring and blunting: Validation of a questionnaire to assess styles of information seeking under threat," Journal of Personality and Social Psychology, vol. 54, pp. 142-148, 1987.

[12] N. Ke, Q. He, and J. Ca, "Nursing staff's research on X-ray radiation protection," Journal of Nursing, vol. 46, no. 5, pp. 83-95, 1999.

[13] H. Wei, Senior Career Learning, New Taipei City National Open University, 2015. 
[14] D. Zhang, Community University: Theory and Practice, Taipei: Shida Bookshop, 2001.

[15] J. Lu, "106 kinds of benefits brought about by physical fitness," Taiwan Provincial School Sports, vol. 47, pp. 17-22, 1998.

[16] L. M. Barmgantnrn, "Transformative learning: Fundamrntal concerts," Adult Learning Theory, pp. 17-22, 2003.

[17] J. Mezirow, Education for Perspective Transformation: Women's Reentry Programs in Community Colleges, New York: Center for Adult Education Teachers College, Columbia University, 1975.

Copyright $\odot 2020$ by the authors. This is an open access article distributed under the Creative Commons Attribution License which permits unrestricted use, distribution, and reproduction in any medium, provided the original work is properly cited (CC BY 4.0).

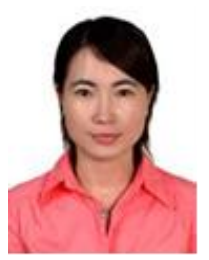

Yen-Ni Tsai was born in 1972. She received her $\mathrm{Ph}$ D. degree in adult education from the School of Education, Chung Cheng University, Taiwan, in 2018. She is currently an associate professor at the School of Education Science, Zhaoqing University, Guangdong, China. Her research interests include adult education, vocational education, theoretical application of teaching technology, teacher development and student affairs.

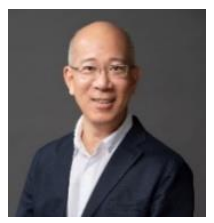

Yeajou Shiau was born in 1961. He received his Ph.D. in manufacturing engineering from Nottingham University, UK, in 2001, and an EMBA degree in ecommerce from National Central University, Taiwan, in 2004. Now, he has taken the associated professor role in marketing, information management and service management studies at Zhaoqing University, Guangdong, China.

He used to be the chief engineer of a mechanical enterprise, responsible for R\&D, design, planning, and information department. He had participated in many projects, such as: ISO9000 quality management system, PDM software development and computerization of design, assisting enterprises in developing e-commerce systems, etc. 